Results: 49 knees (43 pts, median age 70.6 years, 24 women) were included in the study. Kellgren Lawrence grade was 1 for 5 knees, 2 for 10, 3 for 17 and 4 for 9. SHCTH was delivered correctly in the joint space in all patients as assessed by US check during the injection and no side effects occurred. Of the 49 knees, 28 had an available 6 months follow-up, while 21 completed the 12 months follow-up, with an attrition mostly related to the COVID 19 pandemic. A rapid and sustained statistically significant decrease of both VAS pain and the WOMAC subscales was observed. The reduction of pain was already significant at 2 weeks, probably thanks to the corticosteroid component. At US evaluation, effusion significantly decreased at all time points. Although $\mathrm{SH}$ scores also significantly decreased, the effect on the proportion of affected joints was not as relevant. The reduction of PD was significant until month 9. Detailed results are presented in Table 1. Conclusion: Our data show that US guided SHCTH injections provide a rapid and sustained clinical response in patients with symptomatic OA. Besides the effect on pain, the US data confirm the effect of the drug on the inflammation. US guidance guaranteed the correct placement of the product in all patients and eliminated the bias of wrong placement that may occur with blind injections, thus allowing to draw safe conclusions on the efficacy of SHCTH for the treatment of KOA. REFERENCES:

[1] Jones A, Regan M, Ledingham J, et al. Importance of placement of intra-articular steroid injections. BMJ 1993;307:1329-30.

Table 1. Clinical and US measures. $p$ values refer to the comparison with baseline. WOMAC subscales were compared by paired samples $t$ test. *hypothesis test not applicable

baseline 2 weeks 1 month 3 months 6 months 9 months 12 months

VAS (median,IQR) 6 (5-8) 3 (1-4.25) 2 (0.5-3-5) $1.5(0-3) \quad 1.5(0-4) \quad 1(0-2.75) 1$ (0-3.25) $\mathrm{p}<0.0001 \mathrm{p}<0.0001 \mathrm{p}<0.0001 \mathrm{p}<0.0001 \quad \mathrm{p}<0.0001 \quad \mathrm{p}<0.0001$
WOMAC pain

WOMAC stiffness

WOMAC function

Effusion 0-3 2(1-2) (median,IQR)

Synovial

Hypertrophy 0-3

(median,IQR)

PD 0-3 $1(1-2)$ $\begin{array}{lllllll}\mathrm{p} 0.028 & \mathrm{p} 0.0004 & \mathrm{p} 0.0036 \mathrm{p} 0.0096 & \mathrm{p} 0.0064\end{array}$

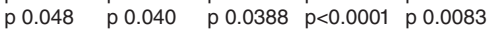
$\begin{array}{lllll}\mathrm{p} 0.043 & \mathrm{p} 0.0005 & \mathrm{p} 0.0014 & \mathrm{p} 0.01 & \mathrm{p} 0.007\end{array}$ $\begin{array}{lllll}\mathrm{p} 0.043 & \mathrm{p} 0.0005 & \mathrm{p} 0.0014 & \mathrm{p} 0.01 & \mathrm{p} 0.007 \\ 1(0-1) & 1(0-1) & 1(0-1) \mathrm{p} & 0(0-1) & 1(0-1)\end{array}$ $\begin{array}{lllll}1(0-1) & 1(0-1) & 1(0-1) p & 0(0-1) & 1(0-1) \\ p<0.0001 & p<0.0001 & 0.0001 & p<0.0001 & p<0.0001\end{array}$ $1(1-1) p \quad 1(1-1) p \quad 1(1-1) p \quad 1(0-1) p \quad 1(0.5-1) p$

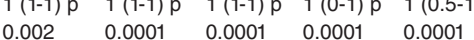

(median, IQR) $0(0-0)$ $0(0-0) \mathrm{p} \quad 0(0-0) \mathrm{p}$ 0.03 0.03
Disclosure of Interests: None declared.

DOI: 10.1136/annrheumdis-2021-eular.3035

\section{AB0599 \\ EFFICACY AND SAFETY OF COMBINATION THERAPY WITH NSAIDS AND ANTICONVULSANT, COMPARED WITH NSAID MONOTHERAPY FOR CHRONIC PAIN IN PATIENTS WITH OSTEOARTHRITIS OF THE KNEE JOINTS}

E. Filatova ${ }^{1}$, L. Alekseeva2, E. Taskina ${ }^{1}$, N. Kashevarova ${ }^{1}$, A. Lila ${ }^{1}$,

E. Sharapova3. 'VA Nasonova Research Institute of Rheumatology, Rheumatology, Moscow, Russian Federation; ${ }^{1}$ VA Nasonova Research Institute of Rheumatology, Rheumatology, Moscow, Russian Federation; ${ }^{1}$ VA Nasonova Research Institute of Rheumatology, Rheumatology, Moscow, Russian Federation

Background: In $20-44 \%$ of patients with osteoarthritis of the knee joints neuroplastic changes occur due to central sensitization $(1,2)$, which is the rationale for complex therapy, including centrally acting drugs, for more effective pain control. Objectives: To evaluate the efficacy and safety of combination therapy with NSAID and anticonvulsant in comparison with NSAID monotherapy in patients with osteoarthritis of the knee joints and signs of central sensitization or nocyplastic pain Methods: The study included 60 women with osteoarthritis of the knee joints (OAK) with signs of nocyplastic pain. Nocyplastic pain were revealed by neuropathic scales (DN4 questionnaire $>4$ points), subject to the absence of patients lesions of the somatosensory nervous system. All patients were randomized into two age- and sex-matched groups: group I $(n=30)$ received combination therapy with aceclofenac and pregabalin, group II $(n=30)$ - monotherapy with aceclofenac. The observation period was 42 days and included three visits. All patients underwent a clinical and neurological examination, we assessed the overall WOMAC index, pain intensity at rest with the visual analogue scale (VAS), nocyplastic pain (DN4 and Pain DETECT questionnaires), anxiety and depression (HADS questionnaire) and the quality of life (EQ-5D questionnaire).

Results: The intensity of pain at rest according to VAS in patients of group I significantly decreased after 14 days (visit 2) and even further after 42 days (visit 3) (64.0 [50.0; 72.0] vs 49.0 [33.0; 55.0] vs 33.5 [22.0; 49.0] p = 0.006). In group II the intensity of pain at rest also decreased after 14 days (visit 2) $(63.0$ [41.0; 72.0] vs 48.0 [35.0; 58.0] $\mathrm{p}<0.001)$, however, did not change significantly from visit 2 to $3(48.0[35.0 ; 58.0]$ vs $44.0[35.0 ; 60.0])(p=0.57)$.

The dynamics of neuropathic pain indicators according to the DN4 and Pain DETECT questionnaires was as follows: group I (visit 1-3) DN4 (6.0 [5.0; 7.0] vs 3.0[1.0; 4.0], $\mathrm{p}=0.001)$ and Pain DETECT $(17.0[16.0 ; 20.0]$ vs $8.0[5.0 ; 14.0]$, $\mathrm{p}=0.001)$. Group II DN4 $(6.0[5.0 ; 6.0]$ vs $5,0[3,0 ; 6,0], \mathrm{p}=0,05)$, Pain DETECT $(17,0[15,0 ; 19,0]$ vs $16.0[14,0 ; 19,0], p=0,53)$.

The overall WOMAC index decreased significantly in both groups.

Significant positive dynamics in terms of the level of anxiety $(9.0[7.0 ; 14.0]$ vs 7.0 [4.0;10.0], $\mathrm{p}=0.001)$, depression (8.0 [5.0;10.0] vs $6.5[4.0 ; 9.0], \mathrm{p}=0.03$ ) and quality of life $(0.52[-0.02 ; 0.52]$ vs 0.52 [0.52;0.59], $p=0.01)$ was observed compared to baseline in group I but not in group II. Before the start of therapy, the groups were comparable in the studied parameters, however, after 42 days, anxiety $(7.0[4.0 ; 10.0]$ vs 9.0 [7.0;12.0], $p=0.02)$ and depression levels $(6.5[4.0 ; 9.0]$ vs 8.0 [6.0;9.0], $p=0.05)$ were statistically different. Moreover, the median anxiety and depression levels still exceeded 7 points in group II, indicating the presence of anxiety and depression. Conclusion: Combination therapy of chronic pain with signs of nocyplastic pain with pregabalin and aceclofenac in patients with knee osteoarthritis has been shown to be effective in terms of pain intensity, the presence of neuropathic descriptors and the severity of anxiety compared with aceclofenac alone.

\section{REFERENCES:}

[1] Hochman JR, French MR, Bermingham SL, Hawker GA. The nerve of osteoarthritis pain. Arthritis Care Res (Hoboken). 2010;62:1019-23.

[2] Hochman JR, Gagliese L, Davis AM, Hawker GA. Neuropathic pain symptoms in a community knee OA cohort. Osteoarthr Cartil. 2011;19:647-54.

Disclosure of Interests: None declared.

DOI: 10.1136/annrheumdis-2021-eular.3062

\section{\begin{tabular}{|l|l}
\hline AB0600 VISCOSUPPLEMENTATION VERSUS PHYSICAL \\
\hline
\end{tabular} REHABILITATION IN KNEE OSTEOARTHRITIS COMPARATIVE STUDY ABOUT 117 CASES}

S. Lahrichi ${ }^{1}$, K. Nassar ${ }^{1}$, S. Janani ${ }^{1} .{ }^{1}$ University Hospital of IBN ROCHD, Rheumatology, Casablanca, Morocco

Background: Viscosupplementation with hyaluronic acid, and physical rehabilitation are part of the adjunct treatments for osteoarthritis, and particularly knee osteoarthritis. They can be used alone or combined.

Objectives: To compare the efficacy of rehabilitation and viscosupplementation in patients followed for stage II and III osteoarthritis.

Methods: This is a cross-sectional study, conducted in the department of rheumatology of the University Hospital oflbn Rochd, Casablanca, between Augus 2020 and December 2020. Inclusion criteria: patients with stage II and III knee osteoarthritis fulfilling the ACR criteria. The diagnosis was made on standard $x$-rays including antero-posterior and lateral views. The functionalassessmentwas made with functional algo indices, WOMAC and Lequesnne. Pain was assessed with a visual analogue scale (VAS) on Day 0 and after 3 months. The patients were divided into 3 groups of 39 patients, the first (G1) received an infiltration of hyaluronic acid according to different protocols (multiple injections or single injection), the second (G2) benefited from a rehabilitation program twiceor three timesa week for three months, and the third group (G3) benefited from viscosupplementation associated with rehabilitation. Patients who received an intra-articular corticosteroid injection in the last 3 months were excluded.

Results: There were 117 patients. The mean age was $59.6 \pm 8.6$, with a female predominance of $96.8 \%$. Knee osteoarthritis was clinically patent for 5.8 years, with an average of 7.4 painful flares. Gonarthrosis was bicompartmental in 52 patients and tri-compartmental in 18 patients. $45 \%$ had a family history of osteoarthritis. $28 \%$ were hypertensive, 18 patients were diabetic and $51.87 \%$ were obese according to the body mass index, with an average of $30.5 \pm 5.2 \mathrm{~kg} / \mathrm{m}^{2}$. $65 \%$ had already received oral anti-arthritis drugs for an average of 1 year. Functional improvement was approximately $38 \%$ in $\mathrm{G} 1,26 \%$ in G2, and $42 \%$ in G3. A significant algo-functional improvement was noted in $\mathrm{G} 1(p=0.04)$ and $G 3$ ( $p=$ $0.03)$. LEQUESNE's index went from an average of 8 in the 3 groups to an average of 4 in 11 and G3 versus 6 in G2, which corresponds to an average handicap $(p=0.2)$. The final value of the WOMAC index in $\mathrm{G} 1$ was 26.57 versus 32.21 in G2 ( $p=0.01)$ and versus 22.36 in $G 3(p=0.02)$.

Conclusion: In our study, the final evaluation showed a decrease in pain and an improvement in functional capacity ranging from 36 to $58 \%$. This improvement in algo-functional indices was significantly more marked in G3[1]. Our study shows that the combination of visco-supplementation with physical rehabilitation gives better results by improving the algo-functional indices than by visco-supplementation alone. Our findings are consistent with the results of the literature[2]

\section{REFERENCES:}

[1] Lebib S, Ben SalahFZ, Ksibi I, Dziri C. The'rapeutiques non me'dicamen-teuses de l'arthrose des membres infe' rieurs: e' tats de lieux et perspectives. RevFr Geriat Gerontol 2006;126(XIII):296-30

[2] Bruyere O, Cooper C, Pelletier JP, Branco J, Luisa BrandiM, GuilleminF, etal. AnalgorithmrecommendationforthemanagementofkneeosteoarthritisinEuropeandinternationally:areportfromataskforceoftheEuropeanSocietyforClinicalandEconomicAspectsofOsteoporosisandOsteoarthritis(ESCEO). Semin Arthritis Rheum. 2014;44(3):253-26

Disclosure of Interests: None declared.

DOI: 10.1136/annrheumdis-2021-eular.3109 